\title{
Mucosal prolapse syndrome-a unifying concept for solitary ulcer syndrome and related disorders
}

\author{
CLAIR EH DU BOULAY, J FAIRBROTHER, PG ISAACSON* \\ From the Department of Pathology, Southampton University Medical School, Southampton SO9 $4 X Y$
}

SUMMARY Nineteen cases of classical solitary ulcer of the rectum syndrome (SURS) and sixteen examples of rectal mucosal prolapse are described. Similarities in the histological and histochemical features of the two groups lead us to suggest that the term "mucosal prolapse syndrome" be used to describe this group of disorders in which mucosal prolapse-overt or occult is the common underlying pathogenetic mechanism.

Solitary ulcer of the rectum syndrome (SURS) is a chronic benign condition characterised by rectal bleeding, the passage of mucus and rectal pain. In its classical form it is a rare disorder which affects young adults. Macroscopically the lesions are typically seen as single or multiple shallow ulcers with hyperaemic margins which are usually situated on the anterior or anterolateral rectal wall. However, ulceration is not always apparent and the mucosa may appear polypoid, or reddened and granular. ${ }^{12}$

Histologically there is disorganisation of the muscularis mucosae with extension of fibromuscular tissue into the lamina propria. The glandular epithelium is hyperplastic and may be villous with telangiectatic blood vessels beneath the surface epithelium.

Histochemically the mucin produced by the glands in this condition has been shown to be abnormal, with sialomucin predominance. ${ }^{3}$

Histological and histochemical features similar to those seen in SURS can be demonstrated in a variety of other conditions and sites, namely transitional mucosa adjacent to large bowel tumours, ${ }^{34}$ prolapsed colostomies ${ }^{4}$ and prolapsed haemorrhoids. This has led us to suggest that SURS is part of a wider spectrum of disorders in which mucosal prolapse is the underlying mechanism. To examine this hypothesis we have compared the clinical, histological and histochemical features of 19 patients with SURS and 16 patients with overt rectal prolapse. The histological similarity of the two conditions is such that we propose the unifying term

*Present address: Department of Morbid Anatomy, School of Medicine, University College London, University Street, London WC1E 6JJ.

Accepted for publication 22 June 1983 "mucosal prolapse syndrome" be used for this group of conditions which share characteristic features.

\section{Material and methods}

All the cases were obtained from the pathology rec- $\frac{3}{0}$ ords at Southampton General Hospital for a period $\stackrel{\Phi}{-}$ covering three years (1978-1981). Two groups of $\vec{\bullet}$ patients were studied. The first consisted of 19 caseg of classical SURS as determined by histology and clinical evidence and the second consisted of 1 cases of overt rectal prolapse.

Histological sections of routinely processed formalin-fixed tissue stained with haematoxylin and eosin were examined by light microscopy in each case. The sections were assessed for the histological features listed in Table 1 . In selected cases from each group, further sections were cut and stained

Table 1 (a) Symptoms in 19 patients with SURS

\begin{tabular}{|c|c|}
\hline \multicolumn{2}{|l|}{ Symptom } \\
\hline \multicolumn{2}{|c|}{$\begin{array}{ll}\text { Rectal bleeding } & 13 / 19 \\
\text { Mucus } & 11 / 19\end{array}$} \\
\hline \multirow{2}{*}{\multicolumn{2}{|c|}{$\begin{array}{l}\text { Abdominal pain } \\
\text { Tenesmus } \\
\text { Prolapse }\end{array}$}} \\
\hline & \\
\hline \multirow{2}{*}{\multicolumn{2}{|c|}{$\begin{array}{l}\text { Prolapse } \\
\text { Regular bowel habit }\end{array}$}} \\
\hline \multirow{2}{*}{\multicolumn{2}{|c|}{$\begin{array}{l}\text { Intermittent bowel habit } \\
\text { Constipation }\end{array}$}} \\
\hline & $\begin{array}{l}3 / 19 \\
6 / 19\end{array}$ \\
\hline
\end{tabular}

(b) Symptoms in 16 patients with rectal prolapse

\begin{tabular}{|c|c|}
\hline Symptom & 우 \\
\hline $\begin{array}{l}\text { Overt prolapse } \\
\text { Bleeding } \\
\text { Haemorrhoids }\end{array}$ & 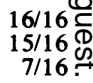 \\
\hline
\end{tabular}

SURS = solitary ulcer of the rectum syndrome. 
with high iron diamine/alcian blue at $\mathrm{pH} 2.5$ (HID/AB).

The clinical notes on all patients were recalled and clinical and historical details were extracted.

\section{Results}

CLINICAL DATA

Table 1 shows the variety of clinical features and their frequency of occurrence in each group.

In the SURS group, there was a marked female preponderance with a ratio of F14:M5. The youngest patient was $12 \mathrm{yr}$ old and the eldest $76 \mathrm{yr}$. In two patients the condition was an incidental finding. The commonest symptoms were rectal bleeding, the passage of mucus and pain. Constipation or an intermittent bowel habit (meaning episodes of constipation, followed by normal or loose stool) was a feature in half the patients. The patients regularly experienced a feeling of prolapse and three patients admitted to self-digitation to assist defaecation.

The 16 patients with rectal prolapse had presented with overt prolapse. Seven of the cases were associated with prolapsed haemorrhoids and rectal bleeding was the commonest symptom. They were all elderly and there was an equal male:female ratio.

\section{SIGMOIDOSCOPIC APPEARANCES OF SURS AND} PROLAPSE

The gross appearances of SURS and their frequency of occurrence are shown in Table 2 . In only 6 of the

Table 2 Gross appearance of SURS and prolapse

\begin{tabular}{llc}
\hline Sigmoidoscopic appearance & SURS & Prolapse \\
\hline $\begin{array}{l}\text { Ulceration } \\
\text { anterior }-3\end{array}$ & $6 / 19$ & $5 / 16$ \\
anterolateral -2 & & \\
posterior -1 & & \\
Granular mucosa & $5 / 19$ & $8 / 16$ \\
Polyp & $8 / 19$ & $1 / 16$ \\
Prolapse & $2 / 19$ & $16 / 16$ \\
Mucus & $6 / 19$ & $0 / 16$ \\
\hline
\end{tabular}

SURS $=$ solitary ulcer of the rectum syndrome.
19 cases was there classical ulceration of the rectum. The ulcers varied in size from $2-3 \mathrm{~mm}$ to $2 \mathrm{~cm}$. Eight of the 19 patients had polypoid rectal lesions and in one of these cases there was florid polyposis. In three cases the position of the polyp varied at subsequent examinations. In the patients with prolapse there was usually reddened polypoid, sometimes eroded mucosa.

\section{HISTOLOGICAL FEATURES}

Table 3 summarises and compares the histological features seen in SURS and mucosal prolapse. The findings were remarkably similar in both groups. Smooth muscle cells and fibroblasts were seen in the lamina propria in all cases (Fig. 1). The glandular crypts showed distortion with branching and shortening. Cytologically the epithelium was always normal but increased mitoses, pseudostratification of the epithelial cells and a varying amount of goblet cell depletion was often present. The muscularis mucosae was thickened and distorted with fibres angulated from the normal plane (Fig. 2). Dilated capillaries were frequently observed beneath the surface epithelium. This was especially marked in those cases where the epithelial surface had developed a villous appearance and in those in the preulcerative phase of SURS. Features such as microerosions, fibrinous membrane formation and trapping of glands or mucin in the submucosa were variably present in both groups.

In three of the cases of SURS where the biopsies were deep enough, abnormalities of arterial walls were noted. The predominant feature was thickening of the vascular media and in one case, fibrinoid necrosis was also present. Lymphangectasia was seen in the submucosa in five cases from group 1 .

\section{MUCIN STAINS}

The results of the mucin histochemistry are shown in Table 4.

The normal rectal mucosa shows a sulphomucin predominant staining pattern with a gradation to sialomucin at the opening of the crypts to the lumen. In both prolapsed mucosa and SURS there is a loss of the normal mucin pattern with sialomucin predominance throughout the crypt length (Fig. 3).

Table 3 Histological features of mucosa in SURS and prolapse

\begin{tabular}{|c|c|c|c|c|c|c|c|}
\hline & $\begin{array}{l}\text { Fibromuscular } \\
\text { proliferation in } \\
\text { lamina propria }\end{array}$ & $\begin{array}{l}\text { Hyperplastic } \\
\text { glands }\end{array}$ & $\begin{array}{l}\text { Thickened } \\
\text { muscularis } \\
\text { mucosae }\end{array}$ & $\begin{array}{l}\text { Telangiectatic } \\
\text { blood vessels }\end{array}$ & $\begin{array}{l}\text { Exudatel } \\
\text { erosion }\end{array}$ & $\begin{array}{l}\text { Glands trapped } \\
\text { in submucosa }\end{array}$ & $\begin{array}{l}\text { Free mucin in } \\
\text { submucosa }\end{array}$ \\
\hline SURS & $19 / 19+$ & $17 / 19+$ & $16 / 19+$ & $14 / 19+$ & $9 / 19+$ & $3 / 19+$ & $4 / 19+$ \\
\hline $\begin{array}{l}\text { Rectal } \\
\text { prolapse }\end{array}$ & $16 / 16+$ & $16 / 16+$ & $14 / 16+$ & $11 / 16+$ & $13 / 16+$ & $3 / 16+$ & $0 / 16+$ \\
\hline
\end{tabular}

SURS $=$ solitary ulcer of the rectum syndrome. 

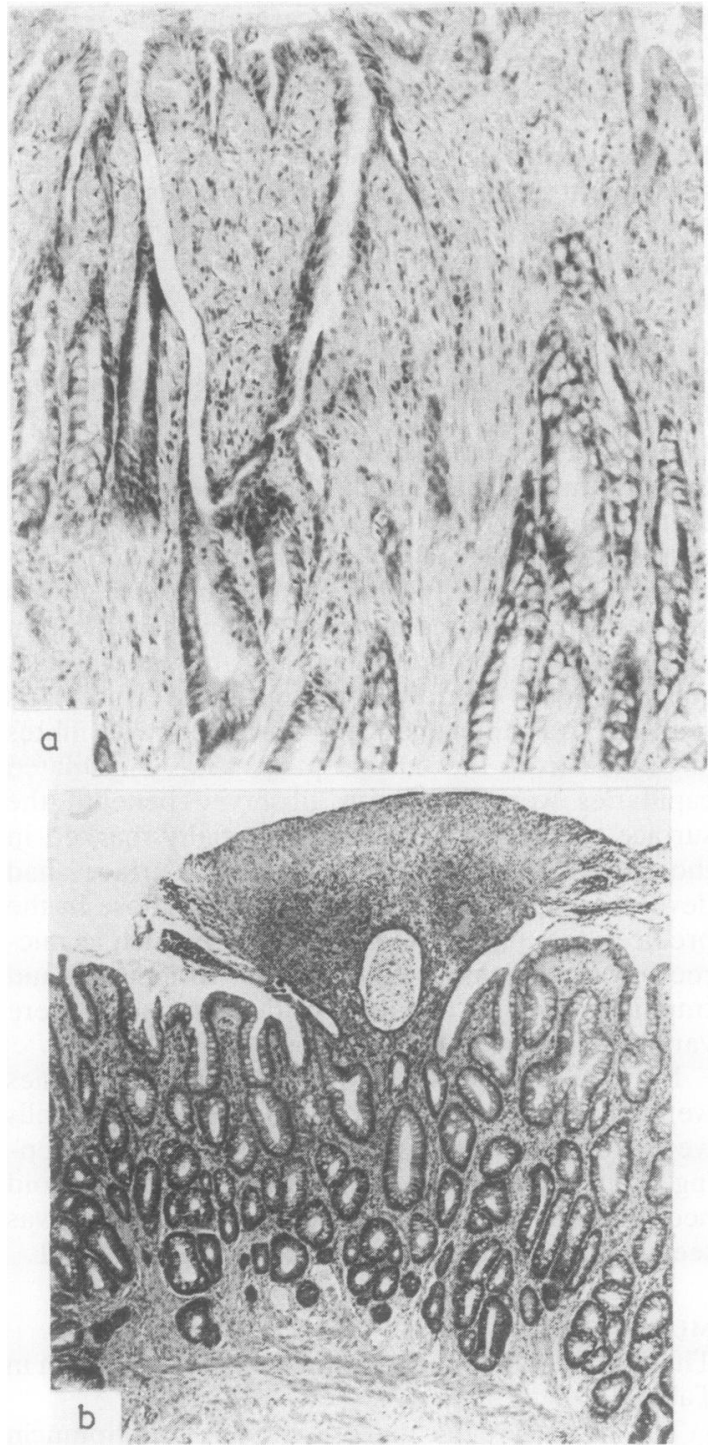

Fig. 1 (a) Mucosa in solitary ulcer of the rectum syndrome. Haematoxylin and eosin. Original magnification $\times 160$. (b) Mucosa in rectal prolapse. Haematoxylin and eosin. Original magnification $\times 60$. Both show branched distorted glands, telangectasia and smooth muscle in the lamina propria.

\section{Discussion}

The earliest descriptions of benign ulceration of the rectum are attributable to Cruveilhier writing in 1832.5 Subsequent case reports ${ }^{67}$ described similar lesions. In retrospect, some of these cases were probably atypical presentations of ulcerative colitis

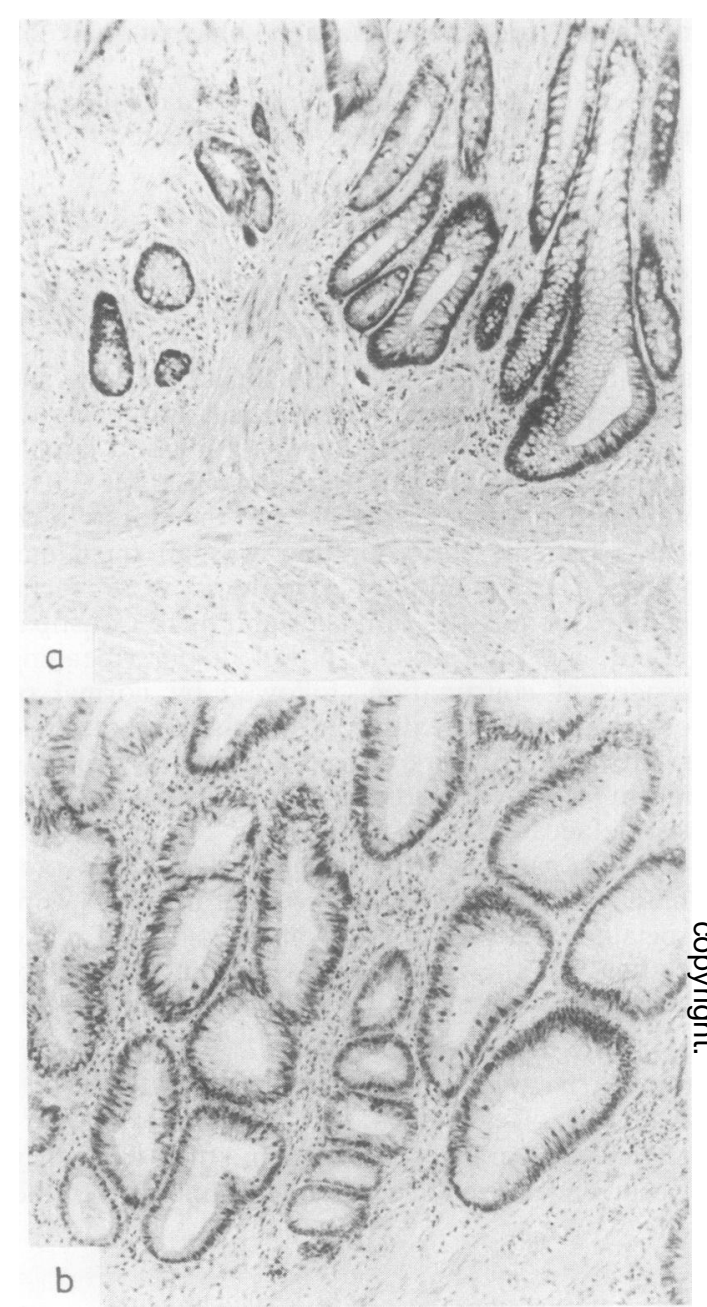

Fig. 2 (a) Solitary ulcer of the rectum syndrome.

Haematoxylin and eosin $\times 160$. (b) Prolapse.

Haematoxylin and eosin $\times 160$. Angulated smooth muscle fibres are shown giving rise to glandular distortion.

Table 4 Mucin histochemistry [HID/AB stain (pH 2.5)]

\begin{tabular}{|c|c|}
\hline & Predominant mucin type \\
\hline Normal mucosa & $\begin{array}{l}\text { Sulphomucin } \\
6 / 6\end{array}$ \\
\hline Mucosal prolapse & $\begin{array}{l}\text { Sialomucin } \\
20 / 20\end{array}$ \\
\hline SURS & $\begin{array}{l}\text { Sialomucin } \\
19 / 19\end{array}$ \\
\hline
\end{tabular}

or Crohn's disease, but there is no doubt that some 0 of them describe features which we now recognise as 0 

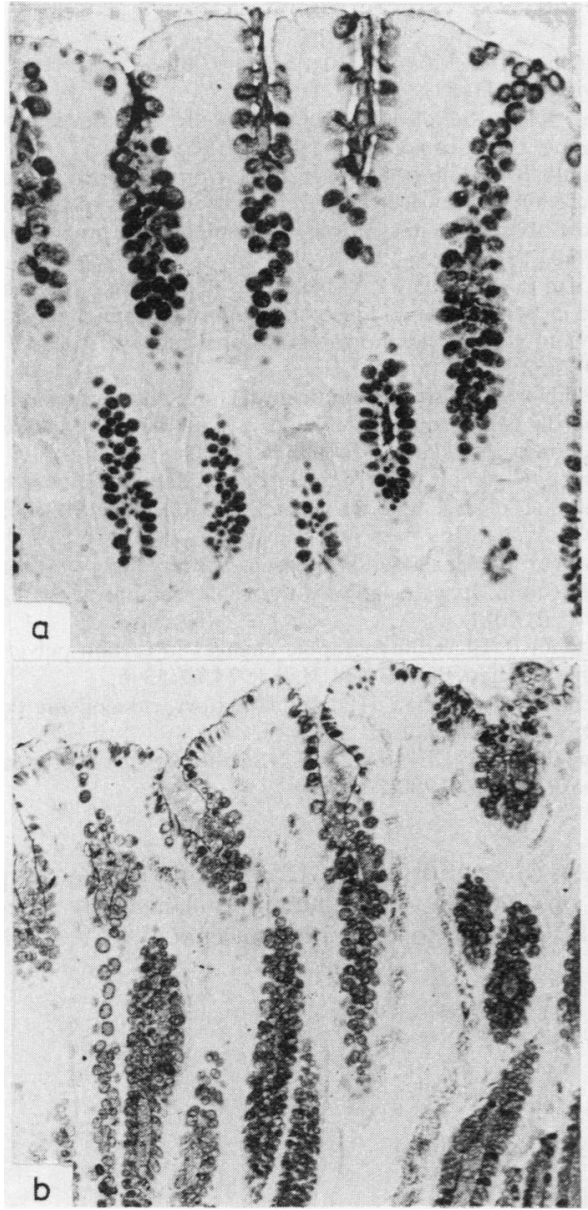

solitary ulcer of the rectum syndrome. The term solitary ulcer was not coined until 1939 when LloydDavies described a group of patients with chronic benign rectal ulceration and recognised this as a distinct clinicopathological entity.

Madigan and Morson definitively described the clinical and pathological features of the syndrome. ${ }^{1}$ In their review of 68 patients, they described single ulcers in $70 \%$ of cases and multiple lesions in $30 \%$ and showed that an ulcerative and preulcerative phase of the condition exist, thus emphasising that solitary ulcer syndrome may not necessarily manifest as either "solitary" or ulcerated lesions. They also described the characteristic histological features of the condition and these have been reiterated more recently by Rutter and Riddell. ${ }^{2}$

Rutter and Riddell first proposed that SURS was due to ischaemia secondary to prolapse of the rectal

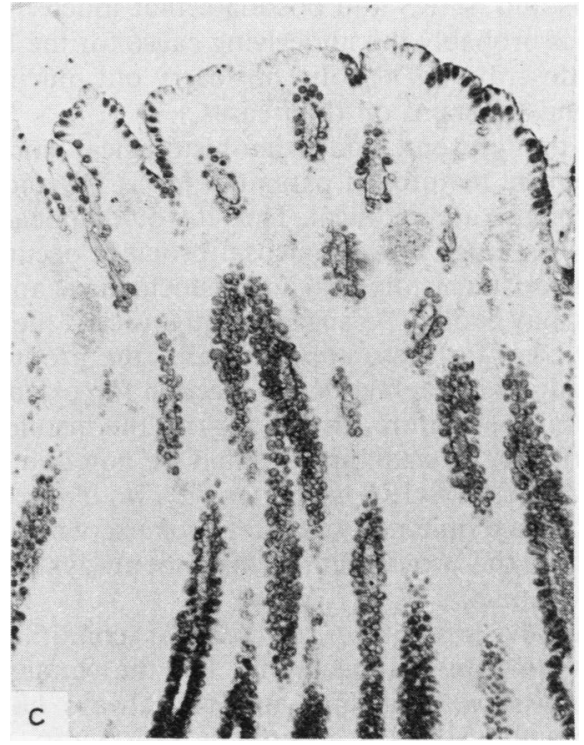

Fig. 3 (a) Normal rectal mucosa showing predominance of sulphomucin. High iron diaminelalcian blue $\times 60$. (b) Solitary ulcer of the rectum syndrome mucosasialomucin predominance. High iron diaminelalcian blue $\times 60$. (c) Prolapsed mucosa. High iron diaminelalcian blue $\times 60$ Sialomucin predominance.

mucosa, and this suggestion was reinforced by Schweiger and Alexander-Williams, who drew attention to the coincidence of SURS and rectal prolapse. ${ }^{8}$ They were able to identify occult rectal prolapse in 12 cases by asking patients to strain with an examining finger held in the rectum. This is a difficult manoeuvre and for this reason prolapse is often overlooked as a causative feature in SURS. Abnormal electromyographic patterns of the pelvic floor have also been demonstrated in patients with SURS. ${ }^{9}$

Histological and histochemical similarities exist between SURS and a number of conditions in which mucosal prolapse is a likely feature. These include "transitional mucosa" 4 and mucosa covering colostomies. Lobert and Appelman, in describing an entity they call inflammatory cloacogenic polyp, draw attention to the close similarity of the histology 
of this and SURS and postulate that mucosal prolapse is probably the underlying cause for the lesion they describe. ${ }^{10}$ They did not carry out mucin histochemistry stains on their cases.

In the present study the histological and histochemical features of patients with SURS and rectal prolapse are identical. Thus it would appear that whenever large bowel mucosal prolapse occurs the characteristic histological and histochemical appearances may evolve. As suggested previously, the most likely basis for these appearances is the production of localised ischaemia due to traction forces on submucosal vasculature. In this regard, the histological abnormality of small arteries that we noted in three of our cases of SURS is of interest. Two of our cases of SURS complained of rectal prolapse which suggests that the two conditions may not always be clinically distinct.

The diversity of terms used for conditions in which prolapse appears to be the underlying mechanism is confusing and not always helpful. Thus, while SURS is a perfectly satisfactory term, terms such as "transitional mucosa", "hamartomatous inverted polyp", "colitis cystica profunda" 1 and "inflammatory cloacogenic polyp" 10 bear no relation to the aetiology of the lesion and are frequently misleading. We propose, therefore, that a common clinicopathological term, mucosal prolapse syndrome, be used to group these conditions together.

\section{References}

' Madigan MR, Morson BC. Solitary ulcer of rectum. Gut 으 1969;10:871-81.

${ }^{2}$ Rutter KRP, Riddell RH. The solitary ulcer of the rectum syndrome. Clin Gastroenterol 1975;4,3:505-30.

${ }^{3}$ Ehsanullah M, Filipe MI, Gazzard B. Morphological and mucus secretion criteria for the differential diagnosis of the solitary ulcer of the rectum syndrome and non specific proctitis. J Clin Pathol 1982;35:26-30.

${ }^{4}$ Isaacson P, Attwood PRA. Failure to demonstrate specificity of the morphological and histochemical changes in mucosa adja- $\infty$ cent to colonic carcinoma transitional mucosa. J Clin Pathol $\overrightarrow{0}$ 1979;32:214-8.

${ }^{5}$ Cruveilhier J. Ulcere chronique du rectum. Anatomie pathologique du corps humain. Volume 2, Number 25. Maladies du rectum page 4. Paris: JB Ballière 1980.

${ }^{6}$ Coombes C. Simple ulcer of the intestine. Thesis Toulouse.1897.

' Quen D. L'ulcer simple du rectum. Rev Chirurg 1902;26:692792.

${ }^{8}$ Schweiger M, Alexander-Williams J. Solitary ulcer syndrome of $\overrightarrow{-}$ the rectum. Its association with occult rectal prolapse. Lancet $\vec{N}$

${ }^{9}$ Rutter KRP. Electromyographic changes in certain pelvic floor $\stackrel{\odot}{\perp}$ abnormalities. Proc R Soc Med 1974;67:53-6.

${ }^{10}$ Lobert PF, Appelman HD. Inflammatory cloagogenic polyps. Am J Surg Pathol 1981;5:761-6.

" Martin JK, Culp CE, Weiland LH. Colitis cystica profunda. Dis Colon Rectum 1980;23:488-91.

Requests for reprints to: Dr Clair EH du Boulay, Depart- $\stackrel{\Phi}{-}$ ment of Pathology, Southampton University Medical $\vec{\varphi}$ School, Tremona Road, Southampton SO9 4XY, England 